\title{
Epileptic seizure discharges in patients after open chamber cardiac surgery - A prospective prevalence study using continuous electroencephalography
}

\section{Marlene Tschernatsch}

Universitatsklinikum Giessen und Marburg Standort Giessen

Martin Juenemann ( $\sim$ martin.juenemann@neuro.med.uni-giessen.de)

Universitatsklinikum Giessen und Marburg GmbH https://orcid.org/0000-0002-8905-3138

Fouad Alhaidar

Kerckhoff-Klinik GmbH

Jasmin El Shazly

Kerckhoff-Klinik GmbH

\section{Marius Butz}

Universitatsklinikum Giessen und Marburg Standort Giessen

\section{Marco Meyer}

Jung Stilling Hospital Siegen

\section{Tibo Gerriets}

Universitatsklinikum Giessen und Marburg Standort Giessen

\section{Markus Schoenburg}

Kerckhoff-Klinik GmbH

\section{Patrick Schramm}

Johannes Gutenberg Universitat Mainz

\section{Research}

Keywords: electroencephalography, cardiac surgery, seizures, epileptic discharges

Posted Date: January 15th, 2020

DOI: https://doi.org/10.21203/rs.2.20961/v1

License: (1) This work is licensed under a Creative Commons Attribution 4.0 International License. Read Full License 


\section{Abstract}

Background Patients undergoing cardiac surgery often develop delirium and postoperative cognitive deficits (POCD), which lead to a higher postoperative morbidity, mortality and a reduced quality of life. Retrospective studies show a higher incidence of delirium, stroke and mortality in patients with convulsive and non-convulsive seizures after cardiac surgery. However, these studies do not systematically detect subclinical seizures in the early postoperative period; so, the incidence of seizures after cardiac surgery remains speculative. To investigate the real frequency of seizures, we conducted this prospective pilot study on patients with open-chamber cardiac surgery using continuous electroencephalography (EEG) monitoring utilizing widely distributed electrodes and 10-channel registration. The main objective of the study is to determine the prevalence of seizure-specific patterns in EEG after elective open-chamber cardiac surgery.

Methods The prospective, blinded, monocentric, observational study investigated patients scheduled for elective open-chamber aortic or mitral valve reconstruction or replacement. The anaesthetic, surgical and postoperative treatment was standardized and not influenced by the presented observation. After surgery, all patients arrived at the ICU, and EEG monitoring started within the first hour after admission to the ICU (10 channel registration: Fp1,Fp2,C3,C4,P3,P4,T3,T4,Fz,Cz). EEG recording was continuously performed for up to 24 hours, and the EEG results were independently analysed with a focus on epileptic discharges and seizure activity by two blinded EEG board-certified physicians

Results One hundred patients were included, $76 \%$ of whom underwent aortic valve replacement, $24 \%$ of whom endured mitral valve reconstruction or replacement. Early postoperative EEG recording lasted $12.9 \pm 7.2$ hours. Epileptic EEG patterns were present in $38 \%$ of patients and seizure-specific EEG patterns were present in $22 \%$ of patients. Main EEG activity at the beginning of recording was suppressed or showed a burst-suppression pattern, and at the end of recording, all patients had an alpha/theta-rhythm.

Conclusion This pilot study reveals a surprisingly high prevalence of seizure-specific EEG patterns (22\%) in patients undergoing open-chamber cardiac surgery. As seizures potentially induce delirium and POCD, this finding is a relevant phenomenon in the post-cardiac surgery population, representing a promising target for the treatment and prevention of postoperative delirium and POCD.

\section{Background}

Patients undergoing cardiac surgery often develop delirium and postoperative cognitive deficits (POCD), which lead to a higher postoperative morbidity, mortality and reduced quality of life [1]. Retrospective studies show a higher incidence of delirium, stroke and mortality in patients with convulsive and nonconvulsive seizures after cardiac surgery [2, 3]. However, these studies consider either clinically obvious, generalised, convulsive seizures or non-convulsive seizures, the latter of which are diagnosed by a corresponding pathological EEG examination; the indication for performing such a standard EEG examination remains unclear. Overall, these studies indicate an incidence of postoperative epileptic 
seizures of $1.0-2.5 \%$ but do not systematically investigate the incidence of subclinical seizures in the early postoperative period. Gofton and colleagues analyse an unselected cardiac surgery collective using a continuous subhairline EEG and find seizures in $3 \%$ of the patients, all of whom underwent openchamber surgery [4]. However, the acquisition of seizures with subhairline electrodes leads to underdetection $[5,6]$. In summary, the incidence of seizures after cardiac surgery remains speculative. Seizures are treatable and, therefore, represent a potential target in the prophylaxis of delirium and POCD.

To investigate the accurate prevalence of seizures, we conducted this prospective pilot study on patients with open-chamber cardiac surgery using continuous EEG monitoring with widely distributed electrodes in a 10-channel registration.

\section{Methods}

This prospective, blinded, monocentric, observational study was conducted at the Kerckhoff-Hospital, Bad Nauheim, Germany. After gaining approval from the ethical committee of the Justus Liebig-University Giessen, Germany, and obtaining written informed consent, consecutive patients scheduled for elective open-chamber aortic or mitral valve reconstruction or replacement were included. Exclusion criteria were emergency surgery, lack of informed consent, pregnancy, pre-existing epilepsy, surgery in deep hypothermia or off-pump surgery. Patients were screened for pre-existing cognitive deficits using the minimental status examination (MMSE) the day before surgery. The anaesthetic, surgical and postoperative treatment was standardised and not influenced by the presented observation. Anaesthesia induction included propofol $2.5-3.0 \mathrm{mg} / \mathrm{kg}$ and sufentanil bolus $0.8-1.0 \mu \mathrm{g} / \mathrm{kg}$. While propofol was applied continuously, remifentanil was added with $0.15-1.0 \mu \mathrm{g} / \mathrm{kg}^{\star} \mathrm{min}$ as continuous analgesia. In addition to continuous remifentanil, sufentanil boli were applied before painful surgical procedures. The target of bispectral index (BIS) was between 40 and 60. To avoid air embolism while finishing cardiopulmonal bypasses, $\mathrm{CO}_{2}$ was inflated into the open heart and air was manually squeezed out. Patients were placed in a Trendelenburg position and the aortic root vent evacuated the air outside of the cavum and the aorta. Transoesophageal echocardiography was used to confirm that no air remained, then the aortal clamp was opened and the patient was positioned horizontally. After surgery, all patients were admitted to the ICU with analgo-sedative drugs (remifentanil and propofol) and invasive ventilation. After establishing the EEG monitoring, propofol and remifentanil were tapered with the target of early extubation. Piritramide and metamizole were used to obtain analgesia.

EEG monitoring started within the first hour after admission to the ICU (EEG-1100-system, NIHON KOHDEN Europe $\mathrm{GmbH}$, Rosbach, Germany). An EEG was performed using 10 cup electrodes (Ag/AgCl) fixed at the scalp with electrode paste following abrasion of the skin surface. The electrodes were placed accordingly to the 10-20 system at Fp1, Fp2, C3, C4, P3, P4, T3, T4, Fz and Cz. EEG recording was continuously performed for up to 24 hours or stopped earlier if patients were discharged from the ICU or if more than 3 electrodes became dysfunctional. Afterwards, the EEG results were independently analysed with a focus on predominant background EEG frequencies, generalised or lateralised epileptic discharges (spikes, sharp waves, sharp-and-waves, spike-and-waves) and seizure-specific patterns (generalised or 
lateralised rhythmic epileptic discharges over a time of more than 10 seconds, long-lasting rhythmic slow waves and generalised rhythmic EEG activity different from the main EEG activity) by two EEG boardcertified physicians (MT, PS) [7]. Both were blinded to patients' treatment and outcome parameters. The EEG interpretation was performed after patients' treatment, so the findings had no influence on the individual therapy. In the case of different interpretations, both investigators analysed the individual pattern together until a consensus was reached.

For secondary analysis, the incidence of delirium was assessed using the confusion assessment method for the intensive care unit (CAM-ICU), performed by nursing staff on the first and second postoperative day. Furthermore, length of stay in the ICU and postoperative strokes up to the end of inpatient rehabilitation were recorded. Doses of clorazepam for premedication, doses of tranexamic acid, time of extracorporeal bypass, aortic clamping time, lowest temperature during cardiopulmonary bypass, intraoperative BIS and mean arterial blood pressure (MAP) were recorded in the anaesthesia protocol and used to detect potentially uncontrollable influencing factors.

\section{Statistical analysis}

Due to the absence of preliminary data, a power analysis could not be performed. For this prevalence study, a sample size of 100 patients was targeted. The prevalence of seizures and epileptic discharges was analysed descriptively. For secondary analysis, a classification was performed for patients with/without epileptic discharges and for patients with/without seizure-specific EEG patterns. It was investigated whether the groups with/without epileptic discharges and with/without seizure-specific EEG patterns differed in patient characteristics (age, gender, BMI), preoperative mental state or intra-operative data. To verify whether the groups differed significantly in categorical variables, chi ${ }^{2}$-tests were calculated on the basis of a dichotomous scale level of the variable. For parametric continuous variables, a student's t-tests were used. Continuous variables that did not meet the criteria of parametric testing were evaluated using Mann-Whitney $U$ test. Normal distribution was proven with the Shapiro-Wilk test and variance homogeneity with the Levene test. For all metric variables, mean values and standard deviation (SD) were reported; for categorically scaled parameters, frequency and percentage were given. Statistical analyses were calculated using SPSS (version 24, IBM ${ }^{\circledR}$ SPSS ${ }^{\circledR}$ Statistics, USA). A significance level with $p<0.05$ was considered to be statistically significant.

\section{Results}

One hundred patients were included, $76 \%$ of whom underwent aortic valve replacement, and $24 \%$ of whom endured mitral valve reconstruction or replacement. Mean age of the patients was $70 \pm 10$ years, $72 \%$ were male, and the mean body mass index was $27 \pm 5 \mathrm{~kg} / \mathrm{m}^{2}$. The American Society of Anesthesiologists physiological status classification was $3.0 \pm 0.2$. Mean MMSE before surgery was 28.3 \pm 1.7 . All patients who gave consent were measured without drop outs due to the primary analysis. Clorazepate was used as premedication in $85 \%$ of the patients $(24 \pm 16 \mathrm{mg})$, and $99 \%$ of the patients received tranexamic acid $(2.8 \pm 0.7 \mathrm{~g}$, max $4.0 \mathrm{~g})$ during the operation. Extracorporeal circulation was 
performed for $112 \pm 37$ minutes with an aortal clamping time of $76 \pm 24$ minutes. EEG recording lasted $12.9 \pm 7.2$ hours per patient, resulting in 1267 hours of EEG data. Five patients remained intubated and were mechanically ventilated at the end of the EEG recording. One of them received $30 \mathrm{mg} / \mathrm{h}$ propofol. Delirium, defined by the CAM-ICU, was observed in 9 patients on day $1(9 \%)$ and 9 patients on day $2(9 \%)$. In 5 patients the delirium existed during both time points.

Thirty-eight percent of the patients showed epileptic discharges like spikes, sharp-and-waves and spikeand-waves, and $22 \%$ displayed seizure-specific patterns, with an inter-observer agreement of $86 \%$ (figure). None of the patients' seizures were observed by the intensive care staff. Main EEG activity at the beginning of the recording time was suppressed or showed a burst-suppression pattern, presumably due to analgo-sedative medication. Whereas, at the end of EEG recording, the main EEG activity in all patients was alpha or theta-rhythm.

Secondary analysis revealed that the prevalence of epileptic discharges or seizure-specific patterns was not associated with the incidence of postoperative delirium during the first two days in a statistically significant way. Patients with seizure-specific patterns had a trend towards a higher risk for delirium on day 1 (relative risk $=2.80 ; 95 \%$ confidence interval $[0.82,9.55] ; p=0.09$ ). Preoperative MMSE indicated normal cognition without evidence of impairment in all patients and did not vary between patients with and without abnormal EEG patterns. The duration of cardiopulmonary bypass, deepest temperature, BIS level and blood pressure due to bypass were not different in patients with epileptic discharges or seizurespecific patterns. Neither the used doses of clorazepate nor tranexamic acid varied in the observed groups. Five patients (5\%) suffered from stroke in postoperative MRI or CT-Scan, 2/38 with and 3/62 without abnormal EEG patterns. The comparison between patients with and without seizure-specific EEG patterns is shown in Table 1. The comparison between patients with EEG abnormalities, including seizure-specific patterns and epileptic discharges, is shown in Table 2. 
Table 1

Comparison between patients with and without seizure-specific electroencephalographic patterns

\begin{tabular}{|c|c|c|c|}
\hline & $\begin{array}{l}\text { Patients with seizure- } \\
\text { specific EEG-patterns } \\
(n=22)\end{array}$ & $\begin{array}{l}\text { Patients without seizure- } \\
\text { specific EEG patterns } \\
(n=78)\end{array}$ & $\begin{array}{l}\mathrm{p}- \\
\text { values }\end{array}$ \\
\hline Gender [f / m] & $7 / 15$ & $21 / 57$ & 0.652 \\
\hline Age [years] & $71 \pm 9$ & $69 \pm 10$ & 0.349 \\
\hline MMSE & $28 \pm 3$ & $28 \pm 1$ & 0.596 \\
\hline $\begin{array}{l}\text { Delirium day } 1 \\
\text { [n/\%] }\end{array}$ & $4 / 18.2$ & $5 / 6.4$ & 0.097 \\
\hline $\begin{array}{l}\text { Delirium day } 2 \\
\text { [n/\%] }\end{array}$ & $2 / 9.1$ & $7 / 8.9$ & 0.986 \\
\hline $\begin{array}{l}\text { Preoperative dose of } \\
\text { clorazepate [mg] }\end{array}$ & $26 \pm 15$ & $24 \pm 15$ & 0.352 \\
\hline $\begin{array}{l}\text { AVR/MVR } \\
{[\mathrm{n}] /[\mathrm{n}]}\end{array}$ & $17 / 5$ & $60 / 18$ & 0.972 \\
\hline $\begin{array}{l}\text { Extracorporeal } \\
\text { circulation } \\
\text { [minutes] }\end{array}$ & $110 \pm 44$ & $114 \pm 37$ & 0.276 \\
\hline $\begin{array}{l}\text { Aortal clamping time } \\
\text { [minutes] }\end{array}$ & $72 \pm 24$ & $78 \pm 24$ & 0.263 \\
\hline $\begin{array}{l}\text { Deepest temperature }\left[{ }^{\circ} \mathrm{F}\right. \\
\left./{ }^{\circ} \mathrm{C}\right]\end{array}$ & $93.2 \pm 35.6 / 34 \pm 1$ & $93.2 \pm 33.8 / 34 \pm 2$ & 0.207 \\
\hline $\begin{array}{l}\text { Time of BIS }<40 \\
\text { [minutes] }\end{array}$ & $58 \pm 34$ & $65 \pm 45$ & 0.620 \\
\hline $\begin{array}{l}\text { Time of MAP }<40 \mathrm{mmHg} \\
\text { [minutes] }\end{array}$ & $7.6 \pm 7.6$ & $8.6 \pm 9.8$ & 0.783 \\
\hline $\begin{array}{l}\text { Doses of tranexamic } \\
\text { acid [g] }\end{array}$ & $2.9 \pm 0.5$ & $2.7 \pm 1.0$ & 0.633 \\
\hline $\begin{array}{l}\text { Lengths of ICU stay } \\
\text { [days] }\end{array}$ & $2.0 \pm 1.8$ & $2.3 \pm 3.5$ & 0.535 \\
\hline \multicolumn{4}{|c|}{$\begin{array}{l}\text { Values given as mean } \pm \text { standard deviation or frequencies (n) and percentage. EEG: } \\
\text { electroencephalogram; f: feminine, m: masculine; MMSE: mini-mental status examination; AVR: aortic } \\
\text { valve replacement; MVR: mitral valve replacement or reconstruction; BIS: bispectral index; MAP: mean } \\
\text { arterial blood pressure; ICU: Intensive Care Unit. Statistical analysis was performed with Mann- } \\
\text { Whitney U-test and chi²-test. }\end{array}$} \\
\hline
\end{tabular}


Table 2

Comparison between patients with and without epileptic discharges and seizure-specific pattern (EEG abnormalities)

\begin{tabular}{|c|c|c|c|}
\hline & $\begin{array}{l}\text { Patients with EEG } \\
\text { abnormalities } \\
(n=38)\end{array}$ & $\begin{array}{l}\text { Patients without EEG } \\
\text { abnormalities } \\
(n=62)\end{array}$ & $\begin{array}{l}\mathrm{p}- \\
\text { values }\end{array}$ \\
\hline Gender $[\mathrm{f} / \mathrm{m}]$ & $9 / 29$ & $19 / 43$ & 0.452 \\
\hline Age [years] & $70 \pm 10$ & $70 \pm 10$ & 0.853 \\
\hline MMSE & $28 \pm 2$ & $28 \pm 1$ & 0.654 \\
\hline $\begin{array}{l}\text { Delirium day } 1 \\
\text { [n/\%] }\end{array}$ & $5 / 13.2$ & $4 / 6.4$ & 0.278 \\
\hline $\begin{array}{l}\text { Delirium day } 2 \\
\text { [n/\%] }\end{array}$ & $5 / 13.2$ & $4 / 6.4$ & 0.278 \\
\hline $\begin{array}{l}\text { Preoperative dose of } \\
\text { clorazepate [mg] }\end{array}$ & $24 \pm 16$ & $25 \pm 15$ & 0.739 \\
\hline $\begin{array}{l}\text { AVR / MVR } \\
\text { [n] / [n] }\end{array}$ & $31 / 7$ & $47 / 15$ & 0.514 \\
\hline $\begin{array}{l}\text { Extracorporeal circulation } \\
\text { [minutes] }\end{array}$ & $110 \pm 43$ & $115 \pm 35$ & 0.246 \\
\hline $\begin{array}{l}\text { Aortal clamping time } \\
\text { [minutes] }\end{array}$ & $73 \pm 26$ & $79 \pm 23$ & 0.167 \\
\hline Deepest temperature $\left[{ }^{\circ} \mathrm{F} /{ }^{\circ} \mathrm{C}\right]$ & $93.2 \pm 35.6 / 34 \pm 2$ & $95.9 \pm 33.8 / 35 \pm 1$ & 0.492 \\
\hline Time of $\mathrm{BIS}<40$ [minutes] & $63 \pm 48$ & $63 \pm 39$ & 0.560 \\
\hline $\begin{array}{l}\text { Time of MAP }<40 \mathrm{mmHg} \\
\text { [minutes] }\end{array}$ & $7.1 \pm 7.0$ & $9.2 \pm 10.5$ & 0.224 \\
\hline Doses of tranexamic acid [g] & $2.9 \pm 0.6$ & $2.7 \pm 1.0$ & 0.287 \\
\hline $\begin{array}{l}\text { Lengths of ICU stay } \\
\text { [days] }\end{array}$ & $1.9 \pm 1.7$ & $2.4 \pm 3.8$ & 0.771 \\
\hline \multicolumn{4}{|c|}{$\begin{array}{l}\text { Values given as mean } \pm \text { standard deviation or frequencies (n) and percentage. EEG: } \\
\text { electroencephalogram; f: feminine, m: masculine; MMSE: mini-mental status examination; AVR: aortic } \\
\text { valve replacement; MVR: mitral valve replacement or reconstruction; BIS: bispectral index; MAP: mean } \\
\text { arterial blood pressure; ICU: Intensive Care Unit. Statistical analysis was performed with Mann- } \\
\text { Whitney U-test and chi²-test. }\end{array}$} \\
\hline \multicolumn{4}{|c|}{ Figure: Frequencies of epileptic discharges in the continuous encephalography after cardiac surgery } \\
\hline
\end{tabular}




\section{Discussion}

The present study shows a surprisingly high prevalence of clinically silent epileptic seizures after openchamber cardiac surgery in this pilot study. Seizure-specific EEG patterns were observed in $22 \%$ of patients and epileptic discharges were observed in $38 \%$ of patients. Patients with seizure activity had a non-significant higher risk for delirium. Further association with age, preoperative mental status, benzodiazepine and tranexamic acid medication or duration of extracorporeal bypass could not be demonstrated. All seizures had no obvious clinical correlate and were not observed by ICU staff. They, therefore, could only be detected by comprehensive EEG monitoring.

We present, for the first time, prospectively assessed EEG data in a representative population undergoing elective open chamber cardiac surgery. The prevalence is higher as the previous published studies did not perform prospective EEG measurements with widely distributed EEG electrodes [2-4] or provide the necessary basis for further investigations regarding the clinical impact of such EEG abnormalities.

The limited sample size of this pilot study might be the reason why no significant association between EEG abnormalities and the incidence of delirium could be objectified, even though the incidence of delirium was more pronounced in patients with seizure-specific EEG patterns. Delirium occurred in $9 \%$ of patients and was therefore considerably less frequent than the $24 \%$ prevalence in the mixed cardiac surgery population described earlier [8]. This observation can likely be explained by the fact that delirium assessment was carried out at specific times by specially trained study stuff and not, as in the present study, in the context of routine patient care by intensive care staff who might underestimate the occurrence of hypoactive delirium that can be harder to identify.

Assessing POCD is time-consuming and places high demands on personnel resources. To avoid under powering in POCD studies, a valid power analysis is necessary. Due to the lack of robust prevalence data of seizures in the population of interest, this pilot investigation was performed without postoperative neurocognitive examinations. POCD is defined as a decline in performance in neuropsychological tests relative to pre-operative performance. Its frequency strongly depends on the follow-up interval and the diagnostic criteria used [9]. After three months, cognitive deficits are still measurable in $16-23 \%$ of patients, and in $31 \%$ of patients undergoing cardiac bypass surgery even after 3 years $[10,11]$. Patients with status epilepticus or repetitive epileptic seizures are known to experience persistent cognitive deficits in memory and learning even one year after the event [12]. Accordingly, the estimated prevalence of POCD $(16-31 \%)$ is approximately in the same order of magnitude as the prevalence of epileptic EEG abnormalities in the present study. In particular, since seizures are potentially treatable with anticonvulsive drugs, the detection and, if necessary, treatment of early postoperative seizures might be of great clinical importance for the incidence of POCD and will be investigated in further trials.

The presented study has some limitations. Patients were not simultaneously monitored by video and the EEG was analysed retrospectively. Since there was no continuous observation of the patients, no clear, direct statement can be made about the convulsive versus non-convulsive character of the seizures. Otherwise, the intensive care staff did not register any convulsive seizures. Artefacts by passive or active 
movement of the patients could also not be dedicated to the observations. The EEG analyser, therefore, widely ignored patterns for typically active or passive movements. Statements about the influence of seizure-specific patterns or epileptic discharges on outcome parameters on the one hand and the influence of perioperative procedures on such EEG abnormalities, on the other hand, cannot be made, as this study was not powered for this purpose. All described secondary calculations in this pilot trial are, therefore, narrative at this point and should be reproduced and systemically evaluated in the context of further studies.

\section{Conclusions}

Postoperative delirium and POCD are relevant complications of open chamber cardiac surgery. The underlying pathophysiology is largely unknown and most likely multifactorial. The present pilot study reveals for the first time a surprisingly high incidence of clinically silent post-operative epileptic seizures. This finding warrants further studies to determine whether postoperative seizure activity contributes to prolonged delirium and POCD and, thus, might represent a promising target for perioperative neuroprotection using anticonvulsive medication. With our data, a power analysis for such studies is now possible.

\section{Declarations}

\section{Ethics approval and consent to participate}

Approval of the ethical committee of the Justus Liebig-University Giessen, Germany, approval number $159 / 14$.

The written informed consent was obtained from all patients.

\section{Consent for publication}

Not applicable

\section{Availability of data and materials}

All data generated or analyzed during this study are included in this published article and its supplementary information files

\section{Competing interests}

The authors declare that they have no competing interests

\section{Funding}

The study was unrestrictedly supported by NIHON KOHDEN Europe GmbH (Rosbach, Germany) by a loan agreement for the EEG monitor. 


\section{Authors' contributions}

MT designed the study, performed data acquisition, analysed the EEGs and analysis and edited the manuscript.

MJ designed the study, performed data acquisition and analysis and edited the manuscript.

PS designed the study, performed data acquisition and analysis, analysed the EEGs and wrote the manuscript.

MB, JE performed data acquisition and statistical analysis and edited the manuscript

FA performed data acquisition and edited the manuscript

TG, MS designed the study and analysis and edited the manuscript

MM performed analysis and edited the manuscript.

\section{Acknowledgement}

Data presented in this manuscript are part of a doctoral thesis presented by Fouad Alhaidar

\section{Authors' information}

Not applicable

\section{Abbreviations}

AVR

aortic valve replacement

BIS

bispectral index

CAM-ICU

Confusion Assessment Method for the intensive care unit

EEG

electroencephalography

ICU

intensive care unit

MAP

mean arterial blood pressure

MMSE

Mini-Mental Status Examination

MVR

mitral valve replacement 
POCD

post-operative cognitive deficits

\section{References}

1.

Berger M, Terrando N, Smith SK, Browndyke JN, Newman MF, Mathew JP. Neurocognitive Function after Cardiac Surgery: From Phenotypes to Mechanisms. Anesthesiology. 2018;129(4):829-51.

2.

Manji RA, Grocott HP, Leake J, Ariano RE, Manji JS, Menkis AH, Jacobsohn E. Seizures following cardiac surgery: the impact of tranexamic acid and other risk factors. Can J Anaesth. 2012;59(1):6-13.

3.

Goldstone AB, Bronster DJ, Anyanwu AC, Goldstein MA, Filsoufi F, Adams DH, Chikwe J. Predictors and outcomes of seizures after cardiac surgery: a multivariable analysis of 2,578 patients. Ann Thorac Surg. 2011;91(2):514-8.

4.

Gofton TE, Chu MW, Norton L, Fox SA, Chase L, Murkin JM, Young GB. A prospective observational study of seizures after cardiac surgery using continuous EEG monitoring. Neurocrit Care. 2014;21(2):220-7. 5.

Young GB, Sharpe MD, Savard M, Al Thenayan E, Norton L, Davies-Schinkel C. Seizure detection with a commercially available bedside EEG monitor and the subhairline montage. Neurocrit Care. 2009;11(3):411-6.

6.

Tanner AE, Sarkela MO, Virtanen J, Viertio-Oja HE, Sharpe MD, Norton L, Davies-Schinkel C, Young GB. Application of subhairline EEG montage in intensive care unit: comparison with full montage. J Clin Neurophysiol. 2014;31(3):181-6.

7.

Hirsch LJ, LaRoche SM, Gaspard N, Gerard E, Svoronos A, Herman ST, Mani R, Arif H, Jette N, Minazad Y, et al. American Clinical Neurophysiology Society's Standardized Critical Care EEG Terminology: 2012 version. J Clin Neurophysiol. 2013;30(1):1-27.

8.

McPherson JA, Wagner CE, Boehm LM, Hall JD, Johnson DC, Miller LR, Burns KM, Thompson JL, Shintani AK, Ely EW, et al. Delirium in the cardiovascular ICU: exploring modifiable risk factors. Crit Care Med. 2013;41(2):405-13.

9.

Rudolph JL, Schreiber KA, Culley DJ, McGlinchey RE, Crosby G, Levitsky S, Marcantonio ER. Measurement of post-operative cognitive dysfunction after cardiac surgery: a systematic review. Acta Anaesthesiol Scand. 2010;54(6):663-77.

10. 
Evered L, Scott DA, Silbert B, Maruff P. Postoperative cognitive dysfunction is independent of type of surgery and anesthetic. Anesth Analg. 2011;112(5):1179-85.

11.

Knipp SC, Matatko N, Wilhelm H, Schlamann M, Thielmann M, Losch C, Diener HC, Jakob H. Cognitive outcomes three years after coronary artery bypass surgery: relation to diffusion-weighted magnetic resonance imaging. Ann Thorac Surg. 2008;85(3):872-9.

12.

Power KN, Gramstad A, Gilhus NE, Hufthammer KO, Engelsen BA. Cognitive function after status epilepticus versus after multiple generalized tonic-clonic seizures. Epilepsy Res. 2018;140:39-45.

\section{Figures}

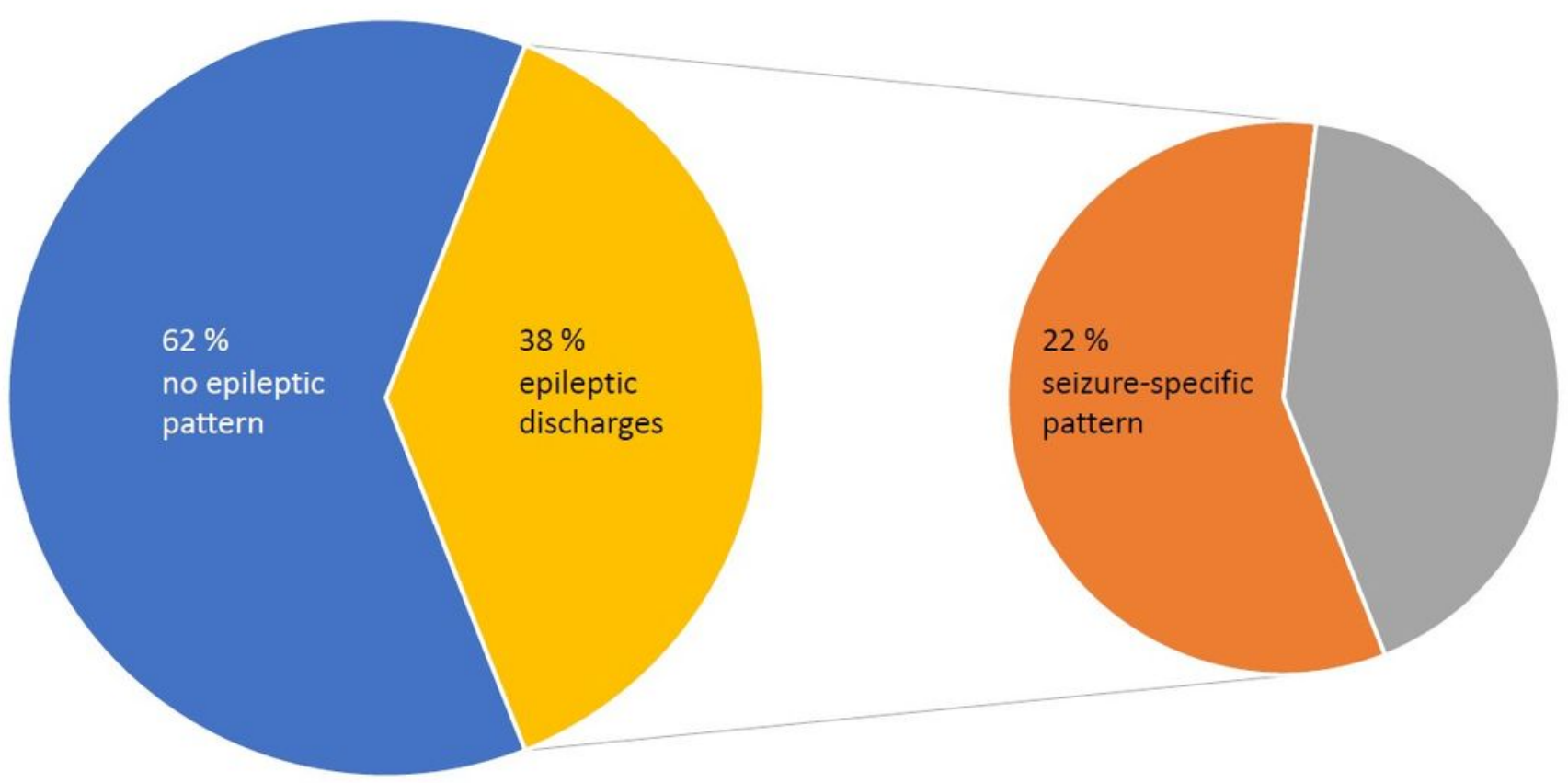

\section{Figure 1}

Frequencies of epileptic discharges in the continuous encephalography after cardiac surgery In the population of 100 patients who underwent open chamber cardiac surgery, 38\% showed epileptic discharges in the early postoperative continuous electroencephalography, $22 \%$ presented seizure-specific EEG patterns. 